\title{
Resonancias del poema Espacio. Juan Ramón Jiménez en los otros; los otros en Juan Ramón Jiménez
}

\author{
Luis PARDIÑAS BÉJAR \\ Embajada de España en Eslovaquia
}

\begin{abstract}
RESUMEN
Juan Ramón Jiménez es uno de los más influyentes poetas del siglo XX. A la vez que alentó la renovación de la poesía española, su obra refleja las tendencias y preocupaciones de la poesía europea de su momento. El poema Espacio es una buena muestra de renovación y universalidad, especialmente en el uso del fluir de la conciencia.

Palabras clave: Juan Ramón Jiménez, Espacio, poesía, monólogo interior, fluir de la conciencia, H. Broch, T. S. Eliot, J. Joyce, O. Paz, Quevedo.
\end{abstract}

\begin{abstract}
Juan Ramón Jiménez is one of the most influent poets in the XX century, he influence the renovation of the Spanish poetry and he was according of the new ways of the European poetry. His poem Espacio is a good piece to view how is present in Juan Ramon the best Spanish tradition in poetry, his leadership about the new Spanish poets and the confluence with the Europeans contemporary topics, especially in the stream of consciousness.
\end{abstract}

Keywords: Juan Ramón Jiménez, Espacio, poetry, stream of consciousness, H. Broch, T. S. Eliot, J. Joyce, O. Paz, Quevedo.

Toute conscience est donc mémoire - conservation et accumulation du passé dans le présent. (Henri Bergson)

En el año 2008 se cerró el trienio de conmemoraciones en torno a Juan Ramón Jiménez, enmarcado desde el cincuentenario de la concesión del premio Nobel hasta el de su muerte. Entre las muchas actividades desplegadas para recordar su obra, hubo una mesa redonda en el auditorio Richelieu de la universidad de la Sorbonne de París en 2007 y un simposio en la universidad Comenius de Bratislava al año siguiente en los cuales se presentó, con diferentes variantes, este artículo que ahora se publica en una versión revisada y que quiere ofrecer una lectura personal de este poeta mayor de la lengua española. 
Nacido en 1881 y fallecido en $1958^{1}$, Juan Ramón Jiménez obtuvo el premio Nobel en 1956, a la quinta nominación, "por su poesía lírica, que en el lenguaje español constituye un ejemplo de elevado espíritu y pureza artística", según la Academia Sueca. Y acaso no esté de más señalar, aunque sólo sea para enmarcar la relevancia de la figura de Juan Ramón, que entre los nominados de ese año encontramos los nombres de Ezra Pound, Albert Camus, Graham Greene o Jorge Luis Borges, y, como candidato de la España oficial, el del eminente filólogo Menéndez Pidal.

Para subrayar su importante contribución a la poesía contemporánea, de toda la obra poética de Juan Ramón Jiménez hemos escogido el poema Espacio ${ }^{2}$. Se trata de un largo poema en prosa de su creación final ${ }^{3}$, que forma parte del poemario $E n$ el otro costado; título que, a su vez, refiere poéticamente el exilio de Juan Ramón y, por tanto, el nuevo espacio desde el cual el poeta recrea aquél otro que hubo de abandonar definitivamente a consecuencia de la guerra civil española.

No parece exagerado decir, tras una lectura reposada y atenta, que este poema Espacio, en el que se advierte de principio a fin la exigencia poética de Juan Ramón Jiménez, supera toda la tradición poético-literaria española, universaliza nuestra poesía, la abre y la conecta con las corrientes más modernas de la literatura contemporánea. Y esto es lo que se quiere referir en este artículo, y de ahí el título escogido.

\section{Juan Ramón Jiménez en los otros}

"Los dioses no tuvieron más sustancia que la que tengo yo."

De esta manera, con esta rotunda, inapelable afirmación, construida en el clasicismo del heptasílabo y el endecasílabo enlazados ${ }^{4}$, comienza y acaba este largo monólogo en prosa de Juan Ramón, verdadero fluir de la conciencia, pautado en tres partes, como si de una pieza musical se tratase, y, como la música, perfectamente ritmado. Fluir de la conciencia, sí, pero que está cuidadosamente

\footnotetext{
${ }^{1}$ Moguer, 23 de diciembre de 1881 / Puerto Rico, 29 de mayo de 1958.

${ }^{2}$ Hemos utilizado la edición que hizo Aurora de Albornoz para Editora Nacional, Madrid, 1982.

${ }^{3}$ Fue escrito entre los años 1941 y 1942, y publicado en 1954 en la revista Poesía Española.

${ }^{4}$ El gusto de Juan Ramón por el verso impar, herencia del clasicismo, le emparenta con la poesía renovadora de Verlaine: De la musique avant toute chose, / et pour cela préfère l'Impair /Plus vague et plus soluble dans l'air, / Sans rien en lui qui pèse ou qui pose.", declara en su Arte poética (Jadis et Naguère), y si Verlaine considera aún la rima, antepone a ella y a todo otro recurso los elementos sonoros y el ritmo en el poema: De la musique encore et toujours!, declara más adelante, lo que es perfectamente acorde con toda la poesía de Juan Ramón y, en particular, con el poema Espacio, concebido como una sonata íntima en tres partes (Sucesión1-Cantada-Sucesión2).
} 
sostenido por su tempo, su ritmo silábico y su estructura circular, reiterativa, también.

En Piedra de sol, largo poema en endecasílabos, construido como una inmensa frase de 584 versos, sin principio ni fin, escrito por Octavio Paz años más tarde ${ }^{5}$, encontramos no sólo idéntica exigencia formal, sino el mismo fluir de la conciencia y la misma estructura circular: una especie de respuesta al comienzo
"Un sauce de cristal, un chopo de agua, un alto surtidor que el viento arquea, un árbol bien plantado mas danzante, un caminar de río que se curva, avanza, retrocede, da un rodeo y llega siempre."

que se repite al final, tras desvelar cuál es su origen y causa: el sol que con su poder divino da vida a todos los elementos

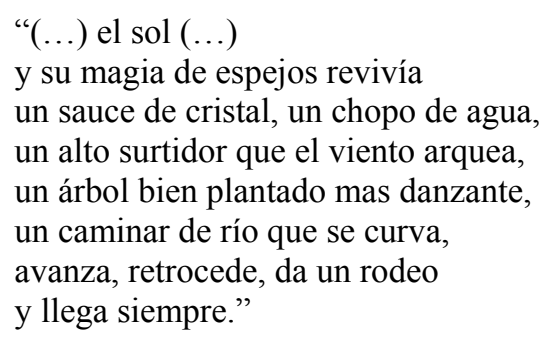

Señalada la similitud que considero radical de ambas obras, querría ahora referirme a algunas diferencias que evidencian en sí mismas la distinta orientación de ambos escritores.

Si en Octavio Paz todo emana del sol y el sol es el centro y está en cada cosa, Juan Ramón desplaza ese centro hacia el hombre, y la deidad es inmanente al yo de Espacio, que rivaliza en poder con los dioses y se adelanta a ellos:

"¿Qué sustancia le pueden dar los dioses a tu esencia, que no pudiera darte yo"? En esta pregunta que dirige, al final del poema, a su interlocutor, que no es otro que su conciencia, antes de cerrarlo con la reiteración de la afirmación que ya hemos visto, el poeta, a la vez que reclama para sí el alto deber de la creación poética, afirma la divinidad del hombre, del yo, en la comunión perfecta de materia y espíritu, de cuerpo y conciencia. Y de esta manera, además, Juan Ramón

5 Antes de la publicación de la obra completa de Espacio en la edición señalada, los fragmentos primero y segundo, en forma de verso libre, habían sido publicados en México precisamente (Cuadernos Americanos, 1943). 
individualiza la pluralidad: en el Yo está todo. Mientras, en Octavio Paz la consideración se presenta al revés: el Yo forma parte del todo:

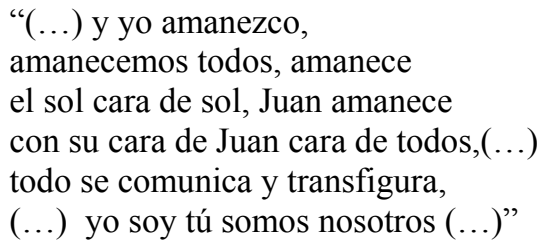

Y visto esto, podemos deducir que la misma identidad compositiva de Espacio y de Piedra de sol, la circularidad señalada anteriormente, es más bien una diferencia sustantiva en ambos: reiteración soberbia del poder del hombre en Juan Ramón frente a la concepción vital del recomienzo, del eterno retorno, podríamos concluir, en Octavio Paz.

La última diferencia que quisiera señalar en estos dos poemas, tan paralelos por otra parte, es el lamento final ante el miedo al abandono que se deja sentir en Espacio, y que es más una queja airada, arrogante, como acaso corresponde a un hombre del temperamento de Juan Ramón Jiménez:

\begin{abstract}
"Mi cuerpo no se encela de ti, conciencia (...) ¿No te apena dejarme? ¿Y por qué te has de ir de mí, conciencia? ¿No te gustó mi vida? Yo te busqué tu esencia. ¿Qué sustancia le pueden dar los dioses a tu esencia, que no pudiera darte yo? Ya te lo dije al comenzar: "Los dioses no tuvieron más sustancia que la que tengo yo.»»"
\end{abstract}

En Piedra de sol, muy al contrario, no hay aflicción sino celebración final: la del sol y su fuerza revivificadora que hace revivir todo y que anuncia además lo que poco después será el himno futuro del poeta mexicano.

Más allá de lo dicho, y considerando, para acabar este apartado, la concepción y significado del poema Espacio, resulta importante señalar el papel central que en él tiene la conciencia y cómo Juan Ramón ve en ella la fuerza necesaria (hecha de voluntad e inteligencia: "memoria son los sueños, pero no voluntad ni intelijencia") que lleva al recuerdo y le trae, recreada, la vida, que en él es un tiempo pasado que se recupera y revive en ese espacio presente del poeta en su vejez. Y por eso, Nueva York no puede ser ya otra que Moguer; y bajo el Washington Bridge no corre el Hudson, sino "el campo amarillo de mi infancia", mientras en la esquina de Broadway le espera al poeta el viento de la Esquina de las Pulmonías de su calle Rascón.

\title{
2. Los otros en Juan Ramón Jiménez
}

"Cuándo tú quedes libre de este cuerpo, cuando te esparzas en lo otro (¿qué es o otro?), ¿te acordarás de mí con amor hondo (...)? ¿Se percibe el tópico del amor 
más poderoso que la muerte de Quevedo? Pues aún se acerca más a él Juan Ramón Jiménez en Espacio unas líneas más adelante:

"Difícilmente un cuerpo habría amado así a su alma, como mi cuerpo a ti, conciencia de mi alma".

Con toda claridad está contenido aquí este tema que remonta Propercio en sus Elegías a Cinthia ${ }^{6}$, recreado por Quevedo en su conocido soneto, que culmina en los tercetos en una verdadera obra de ingeniería sintáctica:
Alma a quien todo un dios prisión ha sido, venas que humor a tanto fuego han dado, medulas que han gloriosamente ardido,
su cuerpo dejará, no su cuidado; serán ceniza, mas tendrá sentido; polvo serán, mas polvo enamorado ${ }^{7}$.

No obstante la similitud de origen, Juan Ramón da la vuelta a este tópico literario, pues de lo que duda es de que la conciencia -el alma- sea capaz de llevar el amor consigo a la otra orilla. Las médulas del soneto de Quevedo, que forman parte del

\footnotetext{
6 "Ut meus oblito pulvis amore vacet” (Propercio, Elegías, Libro I, elegía XIX, v. 6).

${ }^{7}$ En otro conocido y hermoso soneto, menos hermético también, recrea Quevedo el amor más fuerte que la muerte. Es el siguiente:
}

AMOR IMPRESO EN EL ALMA, QUE DURA DESPUÉS DE LAS CENIZAS

Si hija de mi amor mi muerte fuese, ¡qué parto tan dichoso que sería el de mi amor contra la vida mía! ¡Qué gloria, que el morir de amar naciese!

Llevara yo en el alma adonde fuese el fuego en que me abraso, y guardaría su llama fiel con la ceniza fría en el mismo sepulcro en que durmiese.

De esotra parte de la muerte dura vivirán en mi sombra mis cuidados, y más allá del Lethe mi memoria.

Triunfará del olvido tu hermosura; mi pura fe y ardiente, de los hados; y el no ser, por amar, será mi gloria. 
sistema nervioso, que transporta por el cuerpo la voluntad y la inteligencia, son fácilmente identificables con la conciencia de Juan Ramón. Pero si Quevedo las inmortaliza en "polvo enamorado" haciéndolas navegar de un terceto a otro, de una a otra orilla, venciendo la corriente del río Leteo, su "ley severa" que obliga al olvido; Juan Ramón duda y se angustia porque teme que la conciencia es incapaz de permanecer en el amor, de inmortalizar el recuerdo.

Dando un salto en el tiempo y saliendo de la lengua española, citaré tres ejemplos de otras tantas obras y escritores contemporáneos de Juan Ramón Jiménez con los que coincide en el tratamiento del fluir de la conciencia y, en dos de ellos, también en sus preocupaciones ${ }^{8}$.

El primero de ellos es Herman Broch, el escritor vienés perteneciente a esa generación centroeuropea lúcida y perdida con el fin del imperio austrohúngaro. Exiliado en Estados Unidos, como Juan Ramón, tras la ascensión de Hitler al poder, Broch es autor de una de las cimas literarias del siglo XX, La muerte de Virgilio, obra casi contemporánea de Espacio.

La muerte de Virgilio es una narración guiada por el larguísimo soliloquio del poeta Virgilio -otro exiliado él también-, quien, en un duermevela en el que se confunde presente y pasado, sueño y vigilia, recuerda horas antes de su muerte su pasado y debate consigo mismo sobre la concepción de la obra literaria y sobre el destino del hombre.

Contrastemos algunos ejemplos que, incluso, hasta parecen intercambiables en una primera aproximación:

\begin{abstract}
"[...] en el hálito de la noche se unía todo, el zumbar de la fiesta y la paz de la montaña y el cabrilleo del mar, el entonces y el ahora, y de nuevo el entonces, fluyendo el uno en el otro, uno y otro confundidos [...]", "Vuelan las olas y los vientos pasan, y los colores de ola y viento juntos cantan, y los olores fuljen reunidos, y los sonidos todos son fusión", leemos en el fragmento tercero de Espacio.
\end{abstract}

\footnotetext{
${ }^{8} \mathrm{Y}$, no obstante, Juan Ramón en su constante afán de afirmar su individualidad creadora y de reclamarse siempre el primero entre sus contemporáneos, acaso no con mucho acierto en esta ocasión, se cuidó de marcar distancias con los otros escritores y maestros del fluir de la conciencia: "Desde muy joven pensé en el luego llamado 'monólogo interior' (...) y en toda mi obra hay muestra constante de ello. (...) Mi diferencia con los 'monologuistas interiores' que culminaron en Dujardin, James Joyce, Perse, Eliot Pound, etc..., está en que para mí el monólogo interior es sucesivo, sí, pero lúcido y coherente.", dice en Tiempo; y añade en flagrante contradicción "Lo único que le falta es argumento."

${ }^{9}$ H. Broch (1979), p. 56. En su versión original, H. Broch (1976), p. 55:

"(Aber) im Nachthauch war alles vereinigt, Festgebraus und Bergestille und das Glitzern des Meeres, das Einst und das Jetzt und wieerum das Einst, eines ins andere einfließen, eines ins andere verflossen $[\ldots] "$.
} 
"[...] suave latía el mundo, latían lo interior y lo exterior, latían las mareas de los días y las noches, latía el gran orden del ser, quedo e impetuoso, sobre cuyo fondo aun las mareas se confunden y callan, fundida en la unidad el tañido de las noches con las tempestades solares del día $[\ldots]^{\prime, 10}$, en réplica Broch.

Y del fondo se eleva la más íntima voz del ser llamando a la verdadera condición del ser humano:

" $i$ Ay del hombre que no se muestra a la altura de la gracia que le acaece, ay del contrito que no soporta su contrición, ay del residuo de ser creado que no quiere despojarse del ente, ay, ni puede hacerlo, porque la memoria apagada persiste también vacía!"11

¿Acaso sería esto mismo lo que también escuchaba en su interior Juan Ramón y reprime en su ciega y orgullosa afirmación de superioridad?

A continuación citaré al poeta inglés Thomas Stearns Eliot, cuya poesía se asemeja a la de Juan Ramón en estructura y musicalidad, y también en contenido. De hecho a Juan Ramón le llegó a interesar la obra del poeta inglés hasta el punto de que tradujo su poema La figlia che piange ${ }^{12}$.

En una de sus obras mayores, Cuatro cuartetos, encontramos posiblemente la mayor semejanza con Espacio, donde el fluir da sentido al universo, que es forzosamente circular. Valga como ejemplo el siguiente fragmento de "Burnt Norton", poema considerado como intelectual y frío pero que en realidad esconde una desgarrada intimidad. En él, el fluir de la conciencia se detiene en una desasosegada reflexión temporal y metafísica, evidencia -como en Broch- de una de las preocupaciones temáticas de Eliot, la misma que atraviesa igualmente el poema de Juan Ramón Jiménez, y que en Eliot también se expresa en una estructura circular:

${ }^{10}$ H. Broch (1979), p. 287. En su versión original, H. Broch (1976), p. 271:

“[...]leise pulste die Welt, pulste Nächte, pulste die große sacht-ungestüme SeinsOrdnung, auf deren Grund selbst die Gezeiten ineinanderverfließen und erschweigwn, zur Einheit verschmolzen der Nächte Glockenton mit den Sonnenstürmen des Tages...".

${ }^{11}$ H. Broch (1979), p. 161. En su versión original, H. Broch (1976), p. 155:

"Wehe dem Menschen, der sich der ihm widerfahrenen Gnade nicht gewaschen zeigt, wehe dem Zerknirschten, der seine Zerknirschung nicht erträgt, wehe dem kreatürlichen Seinsrest, der das Seiende nicht abtun will, ach, nicht abtun kann, weil das ausgelöschte Gedächtnis in Leerheit weiter besteht [...]" .

12 Poema que, como anécdota ya que nos hemos ocupado de Broch, lleva un encabezamiento de la Eneida que llama, también, a la memoria: "O quam te memorem virgo..." 
El comienzo,

"El tiempo presente y el tiempo pasado están quizá presentes en el tiempo futuro y el tiempo futuro contenido en el tiempo pasado.

Si todo el tiempo es eternamente presente todo tiempo es irredimible." 13

se repite al final de la primera parte del poema, con una variante temporal que cierra el círculo

"El tiempo pasado y el tiempo futuro
lo que podía haber sido y lo que ha sido
apuntan a un solo fin, que está siempre presente."14

Por último, y pasando por alto el otro gran maestro incontestable en el uso literario del fluir de la conciencia, Marcel Proust, que nos enseñó cómo a partir de un olor, de un sabor, es posible recrear todo un mundo ya sólo presente en la selección que la memoria -inteligencia y voluntad para Juan Ramón, no lo olvidemos- hace, es forzoso referirse a Joyce, quien, aunque en los antípodas de Juan Ramón Jiménez en tono, estilo y lenguaje, comparte con él una altísima exigencia estilística e igual obsesión por la revisión de sus escritos.

El recurso del monólogo interior alcanza una de sus cimas en el monólogo de Molly Bloom, al final de Ulises, cuando en una noche de insomnio, desordenadamente recrea una vida imposible; y la cama sobre la que trata de reposar, traída desde Gibraltar -ciudad en la que había nacido-, le lleva hasta Dublín -ciudad en la que vive; otra exiliada, pues-, en una metonimia que reproduce a la perfección el mecanismo asociativo del pensamiento, la luna sobre el mar frente a las costas de Tarifa. Tal y como a Juan Ramón la conciencia igualmente desvelada le lleva hasta Nueva York el paisaje luminoso de Moguer. La cama de Molly Bloom, acaso como el ejercicio de la memoria en Juan Ramón y su orgullosa afirmación situándose desesperadamente por encima de los mismos dioses -de Dios-; esa cama que concentra toda su historia, es el resto del naufragio sobre la

${ }^{13}$ T. S.Eliot (1999), p. 191. En su versión original, T. S. Eliot (1974), p. 177:

"Time present and time past

Are both perhaps present in time future,

And time future contained in time past.

If all time is eternally present

All time is unredeemable".

${ }^{14}$ T. S. Eliot (1999), p. 192. En su versión original, T. S. Eliot (1974), p. 178:

"Time past and time future

What might have been and what has been

Point to one end, which is always present" 
que su exilio vital exige la afirmación desgarrada de una vida desaparecida para siempre, y que ella misma descubre en el repetido, urgente, inaplazable "Si" con que había abierto su monólogo y que, de manera circular también aquí, cierra su intenso viaje interior y la obra toda:

"[...]y el mar carmesí a veces como fuego y las puestas de sol gloriosas y las higueras en los jardines de la Alameda sí y todas aquellas callejuelas extrañas y las casas de rosa y de azul y de amarillo y las rosaledas y los jazmines y los geranios y las chumberas y el Gibraltar de mi niñez cuando yo era una Flor de la montaña sí cuando me ponía la rosa en el pelo como hacían las muchachas andaluzas o me pondré una roja sí y cómo me besaba junto a la muralla mora y yo pensaba lo mismo da él que otro y entonces le pedí con la mirada que me lo pidiera otra vez sí y entonces me pregunto si quería sí decir sí mi flor de la montaña y al principio le estreché entre mis brazos sí y le apreté contra mí para que sintiera mis pechos todo perfume sí y su corazón parecía desbocado y sí dije sí quiero Sí." ${ }^{\prime 5 y 12 b i s}$

Y en paralelo a ese "si" desgarrado de Molly Bloom, que es todo voluntad como en Juan Ramón, éste la reclama para que le redima del pasado perdido que le trae la memoria; que le salve del exilio también, de la vejez acaso, y lo sitúe por encima, incluso, de la misma vida, en fiero desafío a la propia condición humana: "los dioses no tuvieron más sustancia que la que tengo yo."

15 J. Joyce (1999). En su versión original (París, 1922):

"and the sea crimson sometimes like fire and the glorious sunsets and the figtrees in the Alameda gardens yes and all the queer little streets and pink and blue and yellow houses and the rosegardens and the jessamine and geraniums and cactuses and Gibraltar as a girl where I was a Flower of the mountain yes when I put the rose in my hair like the Andalusian girls used or shall I wear a red yes and how he kissed me under the Moorish wall and I thought well as well him as another and then I asked him with my eyes to ask again yes and then he asked me would I yes to say yes my mountain flower and first I put my arms around him yes and drew him down Jo me so he could feel my breasts all perfume yes and his heart was going like mad and yes I said yes I will Yes.”

${ }^{12 b i s}$ Aunque sin ser motivo de este artículo, me parece necesario, por revelador de la técnica del stream of consciousness, hacer notar cómo Joyce suprime los nexos oracionales en todo el monólogo para lograr ese efecto de fluir de la conciencia, y cómo al final se remansa el pensamiento con el polisínndeton, en donde la conjunción copulativa tiene por función poner de relieve cada frase, cada recuerdo, que va acompañado del martilleo de ese sí necesario y urgente, única tabla de salvación de Molly Bloom. 


\section{Obras citadas}

BROCH, Herman: Der Tod des Vergil, Frankfurt am Main, Suhrkamp, 1976.

BROCH, Herman: La muerte de Virgilio. Versión de J. M. Ripalda sobre traducción de A. Gregori, Madrid, Alianza editorial, 1979.

ELIOT, Thomas Stearns: Collected poems 1909-1962, Faber and Faber, London, 1974 (reed. 2002)

ELIOT, Thomas Stearns: Poesías reunidas 1909-1962, Versión de J. M. Valverde, Madrid, 2a, Madrid, Alianza editorial, 1999.

JIMÉNEZ, Juan Ramón: Espacio, ed. Aurora de Albornoz, Madrid, Editora Nacional, 1982.

JOYCE, James: Ulises, traducción de Francisco García Tortosa, Madrid, Cátedra (Letras Universales), 1999. 